Administrative Issues Journal: Connecting Education, Practice, and Research, Summer 2017, Vol. 7, No. 1: 66-68. DOI: 10.5929/2017.7.1.5

\title{
A review of For White folks who teach in the hood...and the rest of y'all too: Reality pedagogy and urban education
}

\author{
Jackie Mania-Singer, Ed.D. \\ Oklahoma State University
}

\begin{abstract}
This literature review provides a summary and analysis of Christopher Emdin's For White Folks Who Teach in the Hood...and the Rest of Y'all Too: Reality Pedagogy and Urban Education. Emdin proposes a theory of reality pedagogy and provides a framework, the Seven Cs, for practical implementation of the approach in the urban classroom.
\end{abstract}

Keywords: urban education, culturally relevant pedagogy, diversity

\begin{abstract}
hristopher Emdin is an Associate Professor in the Department of Mathematics, Science, and Technology at Teachers College, Columbia University; Director of Science Education at the Center for Health, Equity, and Urban Science Education; and Associate Director of the Institute for Urban Minority Education at Teachers College, Columbia University. He is an ambassador to the U.S. Departments of Energy and State and is the creator of the \#HipHopEd social media movement. It is through his experience as a secondary science teacher in the Bronx, however, that Emdin frames For White Folks Who Teach in the Hood... and the Rest of Y'all Too: Reality Pedagogy and Urban Education and makes an impassioned challenge to all teachers to radically transform urban education.

Emdin introduces the book with a historical background of the Carlisle Indian Industrial School. At the Carlisle School, Emdin recounts, indigenous youth who were taken from their Native communities were "tamed" - stripped of their traditions and languages and forcefully assimilated to the dominant white culture. Emdin analogizes the experiences of these indigenous youth to that of the students Emdin identifies as the neoindigenous, the youth of color in today's urban classrooms. The neoindigenous, Emdin argues, suffer authoritarian practices reminiscent of the Carlisle school. Through "classroom colonialism" (p. 14) the neoindigenous learn that academic success equates to exhibiting behaviors consistent with traditional school norms. To be successful, students are taught to remove themselves from the culture of the surrounding community, conform to the expectations of the oppressors, and repress the identities they possess outside of the classroom.
\end{abstract}

Emdin proposes a new approach to meeting the needs of the neoindigenous: reality pedagogy. Reality pedagogy is "an approach to teaching and learning that has a primary goal of meeting each student on his 
or her own cultural turf" (p. 27). It recognizes the space outside of the classroom and values the day-today experiences of students as part of the learning process. Reality pedagogy focuses on a shift in power relationships between teachers and students. Though the teacher maintains the role of presenting the content, the cultural identities and psychological, emotional, and academic needs of the students shape the content. Reality pedagogy requires teachers to "unpack their privilege" (p. 15) recognize the power they hold in perpetuating institutional oppression, and reimagine the urban classroom as one in which students' cultural differences, languages, stories, and histories are not erased, but valued.

In the spirit of reality pedagogy, Emdin draws his examples of the approach from the communities in which neoindigenous students live. Emdin compares great teachers to Pentecostal preachers and rap MCs and effective classrooms to neighborhood barbershops. He emphasizes the impact hip-hop culture, artistic expression, and non-biological family bonds have on urban youth and challenges teachers to recognize the world in which the students reside. In Lessons from the Basketball Court, Emdin recounts how evenings spent playing basketball with his students fundamentally changed the way he approached his classroom. To truly understand and engage the neoindigenous, he argues, the lines between the worlds inside and outside of the classroom must be blurred.

Although the first three chapters of For White Folks Who Teach in the Hood focus on developing the theory of reality pedagogy, Emdin's book does not lose sight of the fact it was written for teachers. Nine chapters of the book are dedicated to real-life examples and practical strategies to implement reality pedagogy in the classroom. Merging personal stories from his own public-school experiences and his early days of teaching with research in the field of urban education and detailed instructions for implementation, Emdin presents the Seven Cs, his framework for teaching in urban schools. The Seven Cs, cogenerative dialogue, conversations between the teachers and students to improve the classroom; coteaching, the transfer of teacher and student roles; cosmopolitanism, creating a collective sense of responsibility; context, moving the classroom beyond the school walls; content, modeling the learning process; competition, nontraditional demonstration of mastery; and curation, reflecting on practice (and three other Cs, clean, code switching, and computing, which are included as chapters, but not listed as one of the Seven Cs) may be the most interesting and applicable part of the book for teachers and teacher preparation programs.

Emdin's respect and devotion to the urban youth of our nation is apparent in every chapter. Also evident is his call for all educatorsm, teachers, administrators, and policy makers, to reflect on their own preconceptions about the neoindigenous and their communities. Throughout the book, Emdin addresses what he refers to as the "problematic savior complex" (p. 20) which is often inherent in teachers of students of differing cultures. Harkening back to the Carlisle School, many teachers of the neoindigenous, he argues, feel a sense of responsibility to "fix the poor kids." This perspective incorrectly identifies the neoindigenous as broken. Instead, Emdin stresses, teachers of neoindigenous youth benefit students the most when they recognize the personal biases they bring with them and adopt a worldview that embraces the brilliance of the neoindigenous, a brilliance not often noticed through the lens of traditional school norms. 
Though the title, For White Folks Who Teach in the Hood...and the Rest of Y'a'll Too: Reality Pedagogy and Urban Education may cause discomfort for some readers, it is within this discomfort, Emdin argues, that real transformational change in urban education will occur. This book provides a pragmatic approach for all teachers of urban youth, white or not, to enact this change in the classroom and advocate for transformation at all levels.

\section{References}

Emdin, C. (2016). For white folks who teach in the hood... and the rest of $y^{\prime}$ all too: Reality pedagogy and urban education. Boston, MA: Beacon Press.

\section{About the Author}

Jackie Mania-Singer, Ed.D. (Jackie.mania@okstate.edu) is a visiting Assistant Professor of School Administration at Oklahoma State University. She has experience as a K-12 teacher and administrator, as well as a state-level director. She has researched and presented on educational issues related to curriculum studies, action research, and principal leadership. Her research interests include social network analysis, district central office transformation, and education reform. 